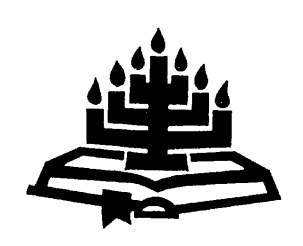

\title{
Een blauwdruk voor de toekomst, Efeziërs 1:9-10
}

\author{
L. Floor \\ Eenheid vir Reformatoriese Teologie \\ Potchefstroomkampus \\ Noordwes-Universiteit \\ POTCHEFSTROOM \\ E-pos: Ifloor@mweb.co.za
}

Abstract

\section{A blueprint for the future, Ephesians 1:9-10}

The aim of this article is to give an explanation of the phrase "anakephalaisasthai ta panta" in Ephesians 1:10. To understand this phrase correctly it is necessary to examine every word of this phrase in order to come to a clearer understanding of the whole phrase. The place of this particular phrase within the thought process of the whole epistle, as well as in the immediate context, will be explored to come to a correct perception of the object under research. Finally an answer will be given to the question whether the teaching of Paul is as vital today as it was in Paul's own day.

\section{Resumé}

\section{Een blauwdruk voor de toekomst, Efeziërs 1:9-10}

Het doel van dit artikel is om een explicatie te geven van de zeer omstreden frase "anakephalaisasthai ta panta" in Efeziërs 1:10. Vanaf het begin van de geschiedenis van de exegese worden we met een zeer uiteenlopende reeks verklaringen van deze frase geconfronteerd. Om deze frase correct te verstaan, is een nauwkeurige exegese van elk onderdeel van deze frase noodzakelijk. Daar benevens moet onderzocht worden wat de plaats van deze frase is in het rede beleid van de hele brief. Daarbij moet de onmiddellijke context waarin de frase geplaatst is ook aan een nauwkeurig onderzoek onderworpen worden. Tenslotte moet er een antwoord gegeven worden op de vraag of het geen Paulus hier leert ook voor de moderne mens van deze tijd even actueel is als in de dagen van de apostel. 


\section{Inleiding}

In zijn boek Between Pentecost and consummation schrijft Professor Tjaart van der Walt dat God "shall lead the universe into a new and endless age where everything and everybody will be perfect and for ever with the Triune God" (Van der Walt, 2009:193).

Van der Walt vertolkt met deze woorden de grote gedachte dat de geschiedenis van al het geschapene, dus inclusief van de mens uitloopt op een majestueuze climax. Niet een verschrikkelijke chaos, maar een onvergelijkelijke harmonie zal de hele schepping doortrekken. Om de persoon aan wie deze bundel is opgedragen te eren en daarmee de waardering voor zijn arbeid als christen-wetenschapper tot uitdrukking te brengen, is voor een onderwerp gekozen, dat direct aansluit bij Professor Van der Walt's visie op de eindtijd.

\section{Vraagstuk en methode}

Het onderwerp is de mededeling van de apostel Paulus in Efeziërs 1:9, 10 dat aan het einde der tijden God op een bijzondere manier in zijn schepping zal ingrijpen. Deze omvattende daad van God is met de volgende frase, "om al wat in de hemelen en op de aarde is onder één hoofd, dat is Christus samen te vatten", geformuleerd. Deze formule wordt door verschillende geleerden beschouwd als de sleutel tot het verstaan van de brief waarin de frase is opgenomen (Scott, 1952:125). Hartin (1986:230) noemt deze tekst het centrale vers van de hele brief aan de Efeziërs.

Aangezien zeer uiteenlopend over de betekenis van de woorden van de apostel Paulus geoordeeld wordt, zal de tekst aan een nauwkerig exgetisch onderzoek onderworpen worden. Daarbij zal de directe contekst en ook de bredere contekst in de vorm van de brief bij het onderzoek betrokken worden.

Hierbij komt ook de vraag aan de orde waarom in een brief die handelt over de kerk, de finaliteit van de schepping besproken wordt.

Ons doelwit is een antwoord te zoeken op de vraag wat de betekenis van deze frase voor de kerk en voor ieder gelovige persoonlijk in deze tijd is.

Met Hartin (1986:228) zijn we van oordeel dat het in het korte bestek van een artikel niet mogelijk is om de vraag naar het auteurschap van de brief in ons onderzoek te betrekken. We gaan uit van het standpunt dat Paulus direct of indirect de auteur van de brief aan de Efeziërs is (Floor, 1998:10-18). 


\section{De onthulling van een geheim}

Wie de brief van de apostel Paulus aan de Efeziërs opslaat en het eerste hoofdstuk leest, wordt door een mate van opgewondenheid bij de auteur getroffen. De schrijver laat zijn lezers weten: "Onthouden jullie het nog? God heeft een geheim en Hij heeft het ons meegedeeld" (Ef. 1:9). Uit dat geheim (letterlijk: het geheimenis van zijn wil), komt aan het licht dat Gods verlossing veel verder reikt dan de vergeving van zonden en daarmee de bevrijding uit de macht van de zonde en de dood. De hele schepping, of om de woorden van Professor Van der Walt te spreken, het "universum", mag delen in de verlossing die Christus verwierf.

Het woord geheimenis (musterion) kan twee dingen betekenen. Het kan wijzen op de geheimleer van de mysteriegodsdiensten waarin men door initiatie ingewijd wordt. Maar het heeft ook de betekenis van een verborgenheid die alleen door goddelijke openbaring gekend kan worden (Floor, 2005:176-179). Het laatste is bedoeld want het gaat hier over een goddelijk geheim, een goddelijk raadsplan. Het plan is lang verborgen gebleven. Het heeft bij wijze van spreken eeuwenlang in Gods la gelegen, maar nu is het dan bekend. Wat God geopenbaard heeft, is niets minder dan een blauwdruk voor de toekomst.

Het is heel belangrijk er op te letten in welke brief de apostel Paulus Gods geschiedenisplan ter sprake brengt. Ook mag het ons niet ontgaan op welke plaats in de brief de apostel Gods plan bepreekt. Paulus bespreekt Gods plan voor de toekomst in de brief aan de Efeziërs.

In deze brief bespreekt de apostel een veelheid van onderwerpen. Bij die grote aantal onderwerpen valt de schijnwerper op de kerk.

Käsemann (1972:12) noemt de brief aan de Efeziërs het klassieke document over de kerk. Het merkwaardige van deze brief is daarbij dat de apostel dit spreken over de kerk in een zeer breed kader plaatst. Hij legt verband tussen de kerk enerzijds en Gods grote heilsplan en de machtspositie van Christus anderzijds. In het allesomvattende werk dat God in Christus Jezus doet, heeft de kerk een eigen plaats. Zij is betrokken bij wat God in Christus in de toekomst gaat doen.

De lezers van deze brief over de kerk gaan de brief door de indrukwekkende poort van een lofprijzing binnen (Ef. 1:3-14). Deze lofprijzing (eulogia) is één lange zin die bestaat uit twaalf verzen. Deze lofprijzing is sterk trinitarisch opgebouwd: het is de Vader die 
verkiest (Ef. 1:4-6), de Zoon die verzoent (Ef. 1:7-12) en de Heilige Geest die verzegelt (Ef. 1:13-14).

In Efeziërs 1:7-10 valt het volle licht op Christus. Tot driemaal toe wordt op Hem gewezen: in wie (Ef. 1:7), in Hem (Ef. 1:9), in Christus (Ef. 1:10). Wat God doet in het heden en in de toekomst doet Hij in en door Christus.

In Efeziërs 1:9-10 borduurt Paulus verder op het stramien van de verlossing van Efeziërs 1:7-8. Hij maakt dan aan zijn lezers duidelijk dat Gods verlossing veel verder reikt dan de vergeving van zonden en daarmee de bevijding uit de macht van de zonde en de dood.

De hele schepping mag delen in het heil dat Christus verwierf. De verlossing in en door Christus is persoonlijk, maar tegelijk ook kosmisch van aard.

Het gaat in deze beide verzen over Gods plan met de wereld. Het is een heilsplan.

Wat God gaat doen, is tot heil van de wereld. Het is tegelijk een geschiedenisprogram (Simpson, 1977:33). Want het plan wordt ten uitvoer gebracht in de volheid van de tijden.

Paulus gaat dan twee belangrijke zaken aan de orde stellen: de bekendmaking van Gods geschiedenisplan (Ef. 1:9); en de inhoud van Gods geschiedenisplan (Ef. 1:10).

\section{De proclamatie van Gods geschiedenisplan}

Paulus schrijft in Efeziërs 1:9 aan zijn lezers dat er een bekendmaking, een proclamatie van Gods kant is geweest. Wat God bekend gemaakt heeft, noemt Paulus "het geheimenis van zijn wil".

God had een geheim en dit geheim had te maken met wat Hij wilde doen. God had Zich iets voorgenomen en dit voornemen stond niet los van Christus, want de apostel schrijft: "dat Hij Zich 'in Hem' had voorgenomen". Het "in Hem" slaat op Christus (Greijdanus, 1949: 33). Bij het goddelijk voornemen, bij zijn plan was Christus ten nauwste betrokken. Het goddelijk voornemen, de ontvouwing en realisering van Gods heilsplan, alles wordt relateerd aan Christus. $\mathrm{Hij}$ is de preëxistente Zoon van God die als Gods Gezalfde het centrum van Gods heilsplan vormt. 


\section{De inhoud van het plan}

Wat is nu precies de inhoud van Gods heilsplan? Het is een plan dat betrekking op de volheid van de tijden heeft. Het bestaat daarin dat God alle dingen onder één Hoofd wil samenvatten (Ef. 1:10). Bij de beschrijving van dit geschiedenisplan gebruikt de apostel drie kernbegrippen die we moeten ontleden om te verstaan wat hij bedoelt. De begippen zijn de voorbereiding, volheid van de tijden en onder één hoofd samenvatten.

\section{De voorbereiding}

Gods plan wordt volgens een bepaald schema ontvouwd. Er zit een duidelijk patroon in. Het staat in betrekking tot (de) bedeling van de volheid van de tijden.

Wanneer we het woord voorbereiding of, zoals het ook wel vertaald wordt bedeling (oikonomia) letterlijk nemen, dan zouden we kunnen zeggen dat het plan van God zeer economisch is. Het woord dat in de oorspronlijke tekst gebruikt wordt, heeft twee betekenissen (Towner, 1993:418). Wanneer het betrekking heeft op een persoon die leiding geeft, betekent het de administratie van een huishouding (oikos). Is iemand ondergeschikt, dan wil het zeggen de verantwoordelijkheid dat alles in het huishouden goed verloopt. Hier is uiteraard de eerste betekenis bedoeld. Het is God die de dingen regelt. Er zijn regelingen nodig in verband met de volheid van de tijden.

\section{De volheid van de tijden}

Het tweede begrip dat de apostel noemt, is de volheid van de tijden. Letterlijk schrijft hij "de economie van het pleroma van de tijden" (kairoi).

Deze vrij ingewikkelde fomulering wil zeggen: wanneer de tijd rijp is voor Gods finale optreden dan moet dit in goede orde, economisch geschieden. Volheid (pleroma) was onder meer een scheepsterm. Het woord werd gebruikt voor de volle lading of voor de volledige bemanning van een schip (Schlatter, 1928:171). Paulus schrijft over volheid van de tijden. Voor tijden gebruikt hij niet het woord chronos, maar het woord kairos. Chronos duidt op tijdsduur in lineaire zin, terwijl kairos "de (eschatologisch gevulde) tijd van de beslissing aangeeft" (Den Hertog, 2005:535).

Paulus spreekt dan over tijden (kairoi) in het meervoud. Eigenlijk is dan de betekenis perioden of gelegenheden (Louw \& Nida, 1988: 639). De tijd doorloopt in allerlei min of meer belangrijke perioden. 
Zowel het aantal als het karakter van de perioden zijn door God bepaald. Hij administreert de tijden of perioden van de geschiedenis. Het aantal perioden in de geschiedenis heeft een maat. Er komt een moment dat deze vol is. Dan is het de volheid van de tijden. Het is de vervulling van alle voorafgaande heilshistorische insnijdingen en keerpunten in de uitgestrektheid van de tijd (Ridderbos, 1966:41). Bruce (1977:33) parafraseert het als volgt: "When all the times and seasons which the Father has fixed by His own authority have ran their course, God's age-long purpose which He planned in Christ will attain its full fruition."

\section{De plaats van Christus in Gods geschiedenisprogam}

Wanneer de maat van de geschiedenis vol is, begint een geheel nieuwe periode. Dan gaat God alles wat in de hemelen en op de aarde is onder één hoofd, dat is Christus samenvatten (Ef. 10). Met nadruk wordt speciaal vermeld dat het hele proces van alles tot één geheel samenvoegen "in Christus" zal plaats vinden.

Bij het begin van de schepping was Christus als het Woord (Joh. 1:1-3) ten nauwste bij het ontstaan van alle dingen betrokken. Bij het einde der tijden is Hij weer bij al het geschapene op een bijzondere wijze betrokken. $\mathrm{Nu}$ is het Christus als het hoofd van zijn lichaam, de kerk (Schlier, 1972:65).

Het gaat hier niet om de heerschappij van Christus over alle dingen. Dat komt later in het vervolg van dit hoofdstuk aan de orde (Ef. 1:2122). Het gaat er in Efeziërs 1:10 daarom dat de geschiedenis, de opeenvolging van perioden en gebeurtenissen in de wereld uitloopt op één grote en massale daad van hereniging of recapitulatie. Alles wordt bijeen gebracht onder één centrale macht. Gods administratie van de geschiedenis heeft één doel. Het is alles op het grote ogenblik gericht waarop Christus alles weer zal herenigen. De uitdrukking in Hem, dit is in Christus, geeft aan dat God handelend optreedt in verbondenheid met Christus. De schrijver van de brief maakt van een formule die zeer centraal functioneert in zijn brieven gebruik (Floor, 1982:9). Het grote werk dat aan het einde der tijden staat te gebeuren, zal en tooi Christooi plaatsvinden. Het is de Christus van kruis en opstanding. Wat meer is het is ook de Christus die als Hoofd boven al wat is, aan de kerk gegeven is (Ef. 1:22). De bemiddelende en verbindende rol van Christus in Gods geschiedenisprogram is zeer troostvol, want Christus is onze Heiland die voor ons stierf aan het kruis en die door zijn opstanding uit de doden verklaard is Gods Zoon te zijn in kracht (Rom. 1:4). Nadat Hij op aarde zijn werk van verzoening in opdracht van zijn Vader heeft 
volbracht, is daar nog een nieuwe taak die voor Hem wacht aan het einde van de tijden. Zijn Vader wil in nauwe samenwerking met de Zoon orde op zaken stellen. Alles ligt in de wereld uit elkaar. Maar nu zal Christus het weer opnieuw bijeen brengen.

\section{Gods herstelplan}

Er moet in de schepping een algehele restauratie plaats vinden. Verschillende nieuwere vertalingen (1951 NBG; 2004 NBG) hebben in Efeziërs 1:10 het woord hoofd ingevoegd, terwijl dit woord in de Griekse tekst niet afzonderlijk vermeld wordt. De vertalers hebben het woord hoofd uit het werkwoord uitgelicht en apart vertaald. We zullen nog zien of dit terecht gedaan is. De apostel gebruikt een heel ingewikkeld werkwoord om Gods geschiedenisprogram te beschrijven, namelijk anakephalaioosasthai.

Het werkwoord anakephalaioo - hier in de infinitief aoristus - heeft een lange geschiedenis. Schlier (1972:681) en Schilder (1947:103107 ) hebben de tocht van dit woord door de geschiedenis nauwkeurig gevolgd. De reis begint al bij Irenaeus en loopt via de Vulgata en John Owen tot diep in de twintigste eeuw. We vinden dit woord bij Aristoteles en in de laat-Griekse literatuur. Over de interpretatie van dit werkwoord is heel wat misverstand ontstaan. Het probleem cirkelt om de vraag of het werkwoord van kephale (hoofd) of van kephalaion (opsomming, samenvatting) afgeleid is. De bovengenoemde bijbelvertalingen hebben voor het eerste woord, het woord hoofd gekozen. De Statenvertaling gaat uit van het tweede woord, opsomming. De geleerden zijn het er over eens dat dit samengesteld werkwoord niet van het woord kephale afgeleid is, maar van kephalaion (Schlier, 1972:681; Gnilka, 1971:80).

Wanneer we voor het tweede woord kiezen, dan betekent het werkwoord opsommen of samenvatten (Hartin, 1986:228-237). Het werkwoord spreekt dan niet van macht of heerschappij maar van een opsomming (bijvoorbeeld van getallen) of een samenvatting (van een bericht). Met Roberts (1991:40) moeten we de vertaling "onder één hoofd samenvatten" als minder juist beschouwen. In het werkwoord horen we "the overtone of renewal" (Brown, 1976:163). De ingewikkelde samenstelling van het werkwoord anakephalaioosasthai maakt het voor ons moeilijk precies vast te stellen wat de apostel met dit woord bedoelt. De sleutel tot het verstaan van dit moeilijke werkwoord ligt volgens Lloyd-Jones (1978:203) in het kleine voorvoegsel weer of opnieuw (ana). Greijdanus (1949:33), Van Leeuwen (1926:30), Hartin (1986:234) en Ridderbos (1966:851) hebben ook bijzondere aandacht aan dit voorvoegsel gegeven. We 
kunnen uit dit voorvoegsel afleiden dat er vroeger wel een eenheid of harmonie is geweest, maar dat die verloren is gegaan. Nu moet opnieuw de eenheid of harmonie weer hersteld worden.

\section{Hoe ziet Gods blauwdruk voor de toekomst er uit?}

Die grote vraag is hoe ver Gods herstelwerk reikt? Paulus spreekt van "alle dingen" (ta panta) die in de hemelen en die op de aarde zijn. Er is over "alle dingen" (ta panta) heel wat geschreven (Meuzelaar, 1979:102). God handelt in Christus met deze wereld. Het vele, de veelheid, alle dingen hebben in Hem hun eenheid. Als dit zo omvattend is dan dringt zich de vraag op of deze wereld het middelpunt van de hele schepping is. We weten sedert Copernicus dat de aarde niet het middelpunt van het heelal is. Al is de aarde dan geen geografisch centrum, het is wel het theologisch-christologische middelpunt (Schilder, 1935:315).

\section{Alle dingen}

Paulus spreekt over "alle dingen" (ta panta) die in de hemelen en die op de aarde zijn. De grote vraag is wat hij daarmee bedoelt en wat dus herenigd wordt. Daarover zijn de meningen zeer verdeeld.

De één denkt aan hereniging van sferen: de hemelsfeer of de sfeer van God en de sfeer van de aarde (Roberts, 1991:40). Reicke $(1970: 890)$ is van mening dat de uitdrukking alles in de schepping en de verlossing omvat. Anderen denken aan alles wat zich in de hemel en op de aarde bevindt: gesternten, engelen, én mensen, dieren, zowel het geestelijke als het stoffelijke, het geringe en het kleine (Geijdanus, 1949:33), terwijl weer anderen de lagere schepping van mineraal, plant en dier niet bij de gedachte van hereniging willen betrekken. Berkhof (1962:41) aanvaart dat alleen mensen en machten voorwerp van Gods verlossingsplan zullen zijn. LloydJones (1978:203) neemt het weer zo breed dat hij alles insluit: engelen in de hemel en zelfs dieren op aarde (hij maakt daarbij onderscheid tussen "animals" en "beasts"). Naar analogie van Kolossenzen 1:15 denkt men dat met de dingen die in de hemel zijn allerlei kosmische, bovenaardse machten bedoeld zijn en met de dingen die op de aarde zijn "al datgene buiten Christus los van Hem dat aan aardse dingen van betekenis wordt geacht voor het heil van de volmaking" (Van Leeuwen, 1926:30). Er is over "alle dingen" heel wat geschreven. We stuiten op een moeilijk begrip, omdat het zo algemeen is. Graber (1975:94-95) zegt dat het concept ta panta "expresses a collective totality. The world remained plurality showing 
many differences and is unified only by the creative sovereignty of God over it."

In 1 Corinthiërs vinden we waarschijnlijk de grondbetekenis van de term, waar het de aanduiding van de hele schepping is en dan de schepping als het werk van God. In het Nieuwe Testament wordt het begrip ta panta in de context van schepping en verlossing gebruikt. Er zijn geleerden die de overtuiging hebben dat de boze machten ook deel van Gods herstelplan zullen uitmaken (Gundry-Volf, 1993: 961). Maar Marshall (1989:312-328) ontkent terecht ten stelligste dat Gode vijandige machten maar op enige manier in Gods geschiedenisplan plaats zouden gekregen hebben. We kunnen veilig aannemen dat Paulus met "alle dingen" alles wat geschapen is, heeft bedoeld.

\section{Er komt een volmaakte harmonie}

Alles in de schepping zal door Christus opnieuw tot een harmonieuze eenheid gebracht worden. Er was onenigheid, disharmonie. De natuur, de geschiedenis en het leven van mensen en volkeren leveren van deze disharmonie een duidelijk bewijs: aardbevingen, overstromingen, droogte, aardverwarming en luchtverontreiniging in de natuur, reeksen van oorlogen en epidemieën in de geschiedenis van de mensheid en twist en tweedracht bij de mensen onderling. Het geheel vertoont een chaotisch beeld. Maar Christus, de Gezalfde van God, zal op grond van zijn heilswerk de harmonie herstellen. Dit betekent niet een soort universalisme in die zin dat alle mensen nu gered gaan worden. Het betekent wel dat Christus' heilswerk ook voor het geschapene van grote betekenis zal zijn. In het Oude Testament zijn hier trouwens al sporen van te ontdekken. Daar wordt Gods reddend ingrijpen ten behoeve van zijn volk verbonden met kosmische gebeurtenissen (Ps. 97:2-6; Jes. 30:7-30). In Jesaja 11:6-9 lezen we de idylle van de wolf en het lam, het kind en de slang. "In Christus" vindt dit alles plaats. Uit de woorden van Paulus blijkt dat Christus een centrale positie ten opzichte van al het geschapene inneemt. De apostel wil de alles omvattende betekenis van Christus voor de toekomst van de schepping aan de orde stellen.

\section{De plaats van de engelen in Gods geschiedenisplan}

De grote vraag is nog hoe het staat met alle dingen (ta panta) in de hemel. Is daar ook disharmonie en moet er orde op zaken gesteld worden? Verschillende Schriftverklaarders betrekken de hemelse dingen op de engelen en dan vragen ze zich af of de hemelgeesten 
die trouw gebleven zijn ook van een bepaalde disharmonie verlost moeten worden. Calvijn (1972:13) heeft een antwoord gegeven op deze vraag. Hij schrijft dat zowel de engelen als de mensen door de genade van Christus tot een vaste orde zijn gebracht.

De mensen waren verloren en de engelen waren niet buiten gevaar. Christus heeft ze beiden met God de Vader verenigd, opdat er een ware harmonie in de hemel en op de aarde zou zijn. In zijn preken over Efeziërs 1:7-10 waar Calvijn (1972:63) wijst op "alle dingen die in hemel zijn", die ook herstel nodig hebben, noemt hij zelfs twee redenen:

Hoewel zij (de engelen) niet van God afgevallen zijn, heeft God toch bij hen dwaling gevonden (Job 4:18) en zonder de voortdurende bijstand van Christus zouden ze ook gevallen zijn. In de tweede plaats door onze zonde waren de engelen onze vijanden geworden en daarom moest Christus optreden om de harmonie ook tussen mens en engel te herstellen.

Het eerste argument klinkt erg speculatief. Het is de vraag of Elifaz wel juist van God gesproken heeft (Job 42:7).

\section{Transformatie}

Nadat de apostel Gods blauwdruk voor de toekomst uiteen gezet heeft, gaat hij meedelen dat de kerk ook betrokken is bij het gigantische, kosmische plan van God. De kerk heeft op een heel bijzondere wijze in Gods plan aangaande de schepping aandeel. Paulus schrijft in Efeziërs 1:11 dat de gelovigen in Hem (Christus) aangewezen (eklèroothèmen) zijn om opgenomen te worden in de herstelde harmonie van de schepping. Wanneer onder Christus alles herenigd wordt, zullen ook de gelovigen daarin delen. Trouwens de Heilige Geest is als onderpand aan hen gegeven (Ef. 1:13).

In Paulus's brief aan de Filippenzen komen we de uitdrukking alle dingen (ta panta) weer tegen. De apostel wil in deze brief zijn lezers overtuigen dat ze niet aan de nieuwe toekomst moeten twijfelen. Wat God aan het einde van de tijden gaat doen, zal geschieden, want de verheerlijkte Christus beschikt over een kracht, letterlijk een energie (energeia) zo groot dat Hij daarmee alles, alle dingen (ta panta) aan Zich kan onderwerpen (Fil. 3:21). Omdat Hij alle dingen aan Zich kan onderwerpen, kan Hij ook het lichaam van de gelovigen veranderen en heerlijk maken (Luter Jr, 1993:868). Het lichaam niet bedoeld als uiterlijk omhulsel van de ziel, maar als de mens als persoon noemt Paulus "een vernederd lichaam" (to sooma tou tapeinooseoos; Fil. 3:21). Het lichaam, de bestaanswijze in het 
aardse leven wordt gekenmerkt door ontluistering en zwakheid vanwege de zonde. Het is een armzalig lichaam (Matter, 1965:94). Maar eens zal daar verandering in komen. Er zal een metamorfose plaatvinden. Christus zal het vernederde lichaam gelijkvorming aan zijn verheerlijkt lichaam maken. Wat Christus zal doen, is een onderdeel van het alles overtreffende harmoniseringsproces dat aan het einde van de tijden plaats zal vinden.

\section{Gevolgtrekking}

In de vorige eeuw hebben met name twee theologen zich bezig gehouden met dit harmoniseringsproces. De theoloog/martelaar Dietrich Bonhoeffer (1986:154) vat op zijn karakteristieke manier wat hier boven besproken is samen. Hij haalt de woorden van de Prediker aan: "God zoekt weer op, wat voorbijgegaan is" (Pred. 3:15). En dan schrijft hij: "lk breng alles terug". Wat betekent: "Ik breng alles terug?" Niets gaat verloren, alles wordt in Christus opgenomen en bewaard, hoewel in een andere gestalte, doorzichtig, helder, bevrijd van zelfzuchtig begeren.

Christus brengt dit alles terug en wel in de staat die God oorspronkelijk bedoelde, zonder de misvorming door onze zonde.

De leer uit Efeziërs 1:10 over de samenvatting en het terugbrengen van alle dingen - anakephalaiosis, recapitulatio (Irenaeus) - is groots en zeer vertroostend. Het "God zoekt terug wat verloren was" gaat in vervulling.

Bonhoeffer is overtuigd dat de gedachte dat God door Christus alles terugbrengt ook troostvol kan zijn voor hen die treuren over dood van hun geliefden. In een van zijn brieven uit de gevangenis (Bonhoeffer, 1964:126) schrijft hij:

Ich glaube, dass diese Gedanke sehr wichtig ist, wenn wir mit Menschen zu sprechen haben, die uns nach dem Verhältnis zu ihren Toten fragen. 'Ich bring alles wieder' - d.h. wir können und sollen es uns nicht selbst wieder nehmen, sondern von Christus geben lassen.

De tweede theoloog die zich intensief met de ontwikkeling in de geschiedenis tot het einde der tijden bezig heeft gehouden, is Cornelis Veenhof. Vooral na de opstanding van Christus ziet hij in het wereldgebeuren een onwikkeling waarbij de gelovigen op een bijzondere wijze betrokken zijn. Zij zijn ingeschakeld in dat grote geheel van werkingen en daden. "Het gaat om een gebeuren, een dadenreeks van volmaakte harmonie, waarin ieder ding, ook al is 
het schijnbaar nog zo klein, zijn eigen vaste plaats ontving. Niets is overbodig, niets is toevallig." (Harinck, 2008:108.) Terwijl Bonhoeffer de christenen tot rustige overgave en geloofsvertrouwen wil brengen, spoort Veenhof de gelovigen tot onvermoeide ijver in het koninkrijk van God aan. Ze zijn immers Gods medearbeiders.

\subsection{De taak van de kerk}

Het is niet zonder reden dat Paulus Gods blauwdruk voor de toekomst in de brief aan de Efeziërs, de brief over de kerk opgenomen heeft. Gods herstelplan is in beginsel reeds op de Hemelvaartsdag begonnen (Schilder, 1947:103). Het bestaan en het karakter van de kerk is daar het bewijs van. Gods heelmaakproces begint in de kerk. Wat van elkaar gescheiden was, wordt in Christus tot een harmoniëuse eenheid hersteld. Christenen uit de heidenen en christenen uit de Joden zijn tot een nieuwe eenheid samengevoegd (Ef. 2:1-22). De kerk heeft tot taak om in een verwarde en verscheurde wereld door haar eenheid in Christus, haar vrede en harmonie te laten zien dat Christus als Hoofd van de kerk, die zijn lichaam is, reeds bezig is met de taak die zijn Vader Hem opgedragen heeft.

\section{Geraadpleegde bronnen}

BERKHOF, H. 1962. Christus en de machten. Nijkerk: Callenbach.

BONHOEFFER, D. 1964. Widerstand und Ergebung: Briefe und Aufzeichnungen aus der Haft. München: Kaiser.

BONHOEFFER, D. 1986. Goede machten. Baarn: Ten Have.

BROWN, C. 1976. Head. (In Brown, C., ed. Dictionary of New Testament Theology. Vol. 2. Exeter: Paternoster. p. 163.)

BRUCE, F.F. 1977. The epistle to the Ephesians. Glasgow: Mohr Scott.

CALVIJN, J. 1972. Uitlegging op de zendbrieven van Paulus. Deel 2. Ed. by A.M. Donner. Goudriaan: De Groot.

DEN HERTOG, G.C. 2005. Tijd. (In Noordegraaf, A., red. Woordenboek voor bijbellezers. Zoetermeer: Boekencentrum. p. 534-539.)

FLOOR, L. 1982. Ons in Christus en Christus in ons. Potchefstroom: PU vir $\mathrm{CHO}$.

FLOOR, L. 1998. Efeziërs: eén in Christus. Kampen: Kok.

FLOOR, L. 2005. Geheim. (In Noordegraaf, A., red. Woordenboek voor bijbellezers. Zoetermeer: Boekencentrum. p. 176-179.)

GNILKA, J. 1971. Der Epheserbrief. Freiburg: Herder.

GRABER, F. 1975. All, many. (In Brown, C., ed. Dictionary of New Testament Theology. Vol. 1. Exeter: Paternoster. p. 94-97.)

GREIJDANUS, S. 1949. De brief van den apostel Paulus aan de Ephesiërs. Kampen: Kok.

GUNDRY-VOLF, J.M. 1993. Universalism. (In Hawtorne, G.F. Dictionary of Paul and his letters. Leicester: InterVarsity. p. 956-969.) 
HARINCK, G., red. 2008. "Niets is overbodig, niets is toevallig": leven en werk van Cornelis Veenhof (1902-1983). Vuurbaak: Barneveld.

HARTIN, P.J. 1986. Anakephalaioosestai ta panta en tooi christooi (Eph. 1:10). (In Petzer, J.H. \& Hartin, P.J., eds. A South African perspective on the New Testament. Leiden: Brill. p. 228-237.)

KÄSEMANN, E. 1972. Der Ruf der Freiheit. Göttingen: Mohr.

LLOYD-JONES, D.M. 1978. God's ultimate purpose: an exposition of Ephesians 1:1-23. Edinburgh: Morrison \& Gibb.

LOUW, J.P. \& NIDA, E.A. 1988. Greek-English Lexicon of the New Testament based on semantic domains. New York: United Bible Societies.

LUTER Jr., A.B. 1993. Savior. (In Hawtorne, G.F. Dictionary of Paul and his letters. Leicester: InterVarsity. p. 867-869.)

MARSHALL, I. 1989. Does the New Testament teach universal salvation? Allison Park: Pickwick.

MATTER, H.M. 1965. De brief aan de Philippenzen en de Brief aan Filémon. Kampen: Kok.

MEUZELAAR, J.J. 1979. Der Leib des Messias. Kampen: Kok.

REICKE, B. 1970. Pas, hapas. (In Kittel, G. \& Friedrich, G., eds. Theological Dictionary of the New Testament. Vol. 5. p. 886-896.)

RIDDERBOS, H.N. 1966. Paulus: ontwerp van zijn theologie. Kampen: Kok.

ROBERTS, J.H. 1991. The letter to the Ephesians. Cape Town: Lux Verbi.

SCHILDER, K. 1935. Wat is de hemel? Kampen: Kok.

SCHILDER, K. 1947. Christus en cultuur. Kampen: Kok.

SCHLATTER, A. 1928. Erläuterungen Eph. Stuttgart: Calver.

SCHLIER, H. 1972. Kephale, anakephalaioosastai. (In Kittel, G., ed. Theological Dictionary of the New Testament. Vol. 3. Grand Rapids: Eerdmans. p. 673-682.)

SCOTT, E.F. 1952. The epistles of Paul to the Colossians, to Philemon, and the Ephesians. London: Hodder \& Stoughton.

SIMPSON, E.K. \& BRUCE, F.F. 1977. The epistles to the Ephesians and Colossians. London: Marshall. (The New International Commentary.)

TOWNER, P.H. 1993. Household and household codes. (In Hawtorne, G.F. Dictionary of Paul and his letters. Leicester: InterVarsity. p. 417-419.)

VAN DER WALT, T. 2009. Pentecost and consummation. Potchefstroom: Potchefstroom Theological Publications.

VAN LEEUWEN, J.A.C. 1926. Paulus' zendbrieven aan Efeze, Colosse, Filemon en Thessalonika. Amsterdam: Bottenburg.

\section{Kernbegrippen:}

eindtijd
eschaton
kerk
kosmos
parousie/wederkomst
restouratie




\section{Key concepts}

church

cosmos

end time

eschaton

parousia/return of Jesus

restoration 